\title{
Exploring Smartphone Addiction: Insights from Long-Term Telemetric Behavioral Measures
}

\author{
http://dx.doi.org/10.3991/ijim.v9i2.4300 \\ Chad Tossell ${ }^{1}$, Philip Kortum ${ }^{2}$, Clayton Shepard ${ }^{2}$, Ahmad Rahmati ${ }^{3}$, Lin Zhong ${ }^{2}$ \\ ${ }^{1}$ US Air Force Research Laboratory, Wright-Patterson AFB, OH, USA \\ ${ }^{2}$ Rice University, Houston Texas, USA \\ ${ }^{3}$ Apple Corporation, Cupertino, CA, USA
}

\begin{abstract}
This study examined smartphone user behaviors and their relation to self-reported smartphone addiction. Thirty-four users who did not own smartphones were given instrumented iPhones that logged all phone use over the course of the year-long study. At the conclusion of the study, users were asked to rate their level of addiction to the device. Sixty-two percent agreed or strongly agreed that they were addicted to their iPhones. These users showed differentiated smartphone use as compared to those users who did not indicate an addiction. Addicted users spent twice as much time on their phone and launched applications much more frequently (nearly twice as often) as compared to the non-addicted user. Mail, Messaging, Facebook and the Web drove this use. Surprisingly, Games did not show any difference between addicted and nonaddicted users. Addicted users showed significantly lower time-per-interaction than did non-addicted users for Mail, Facebook and Messaging applications. One addicted user reported that his addiction was problematic, and his use data was beyond three standard deviations from the upper hinge. The implications of the relationship between the logged and self-report data are discussed.
\end{abstract}

Index Terms - Smartphones, Addiction, Human Behavior, Technology Social Factors.

\section{INTRODUCTION}

Smartphone use is becoming ubiquitous. According to recent statistics, over one billion people worldwide own at least one of these devices [1] and they use them for a wide number of tasks, from placing a phone call to checking email, surfing the web, and listening to music [2]. These technologies have been adopted at a rate faster than any other in history [3] and the web is currently accessed more from smartphones than any other type of device [4].

The iPhone and similar smartphones have been described as addictive technologies [5]. Survey-based research has shown that many respondents would give up brushing their teeth, having sex, exercising, wearing shoes, showering, and eating chocolate instead of living without their iPhone for the same period of time [6]. There have been a number of empirical studies relevant to addiction to smartphones (see [7] for a review) and the prevalence of mobile phone addiction varies widely from study to study, with mobile phone addiction rates reported in the range of $0-38 \%$, depending on the study and the scale used [7]. Researchers also differ in the extent to which mobile phone addiction is actually problematic. Some argue that mobile phone usage is rewarding and, like any other rewarded behavior, the addiction to mobile phones is quite prevalent, but not problematic [8]. This line of thought suggests that smartphones, like the internet, provide access to addictive content (e.g., cybersex, gaming, etc.) but are not the source of the addiction itself $[9,10,11]$. Other researchers suggest that mobile phone addiction is problematic and the use and abuse of the technologies can be detrimental $[12,13,14,15]$.

The variability in the literature regarding smartphone addiction has been attributed to the vagueness of the conceptualization of technology addiction [7,16] and problems associated with confounding behaviors and consequences in clinical studies [17]. Primarily, research applied to understanding smartphone addiction has leveraged survey-based and other ethnographic methods. Indeed, over 18 different scales have been developed to assess the psychological variables underlying the addiction to mobile phones. Most of these scales have been noted as problematic to at least some degree (see [17] for an analysis). Because of the difficulty in exactly defining addiction, some researchers have adopted less controversial descriptions of these behaviors, including "problematic mobile phone usage" and "smartphone dependency". Although these descriptions do not carry some of the negative connotations associated with the clinical label of addiction, we chose to use the term precisely because it describes behaviors that are at once reinforcing and potentially problematic.

Self-reports about smartphone use are commonly used in these clinical studies to ascertain the behaviors and consequences associated with participants' levels of smartphone usage. Yet, there are noted problems with the accuracy of self-reports in general [18] and with recalling behaviors associated with smartphone usage in particular (e.g., compared with how they actually used their phones according to telemetric data [19]). Although the literature is replete with clinical studies of mobile phone addiction assessing individual differences in its onset and manifestation levels, few studies provide a realistic examination of behaviors associated with the addiction captured with logged (telemetric) data.

The purpose of this study was to address this shortcoming with a naturalistic and longitudinal analysis of smartphone addiction using a blended approach including both survey and telemetric data. We took an indepth look at 34 undergraduate students and how they used their smartphone over the course of one year. All of their real usage was recorded via an unobtrusive, in-device logger to reveal patterns associated with potentially addictive behaviors associated with the technology. These data were complemented with survey responses to understand each user's (self-perceived) addiction levels 
and how those manifested in real-world usage patterns. Such an understanding can be helpful for assessing the severity of smartphone addiction and providing a more precise assessment of the specific aspects of smartphones that could be particularly addictive.

\section{A. Research Questions}

This exploratory study examined the existence of smartphone addiction across applications on users' devices. We were interested in two fundamental questions. First, how does self-reported smartphone addiction relate to monthly smartphone use? We hypothesized that self-reported addicts and non-addicts would have different frequency of use patterns, with addicts using their devices more frequently and for longer durations. Second, are there ways to assess addictive behaviors via logged (telemetric) data?

\section{METHODS}

This study applied a quasi-experimental approach using naturalistic and longitudinal usage data collected over a one-year period. A full description of the broader methodology used in this study is described by [19].

\section{A. Participants}

A total of 34 students (19 male, 15 female) participated in the research. These students had diverse academic majors, socioeconomic levels, and ethnicities. Ten of the participants attended a community college and the other 24 students attended a major university in Houston, Texas. We purposefully selected students that did not previously own a smartphone to control for experience with the device. However, all participants owned a laptop and used computers frequently for collegiate studies. All students maintained grade point averages (GPAs) over 3.25.

\section{B. Materials and Measures}

iPhones that ran iOS 3.1.3 were provided to each subject free of charge over the one year study period. A custom logger [20], which operated as a background process and did not interrupt usage, was installed on each iPhone. Data were automatically captured every night with no user interaction. The data we collected included all application launches, the duration of the application launches, and when the application launches occurred (i.e., date/time stamps). More information was collected from several applications, including how many text messages were sent/received, the URLs visited over Safari, and the number of contacts in each participant's Contacts application. Most of the social data collected (contacts, text messages, email, phone calls, etc.) were obfuscated to negate privacy concerns.

A 15-question survey, the Smartphone Addiction Measurement Instrument (SAMI), modeled after the Cellular Phone Addiction Scale (CPAS; [21]) and Internet Addiction Test (IAT; [22]) was administered at the end of the year-long study (Table 1). Participants rated each item on a 5-point Likert scale ranging from never (1) to always (5). The IAT is a well-known instrument validated psychometrically across cultures [23, 24] and the CPAS has also been used in several countries [21]. It should be noted that both scales are somewhat dated; thus, the authors made substantial changes to the items. Additionally, open-ended questions and yes/no questions were also included in the survey to help interpret some of the logged data and understand the nature of any reported addiction. We refrained from introducing novel interfaces, experimenter-constructed tasks, and research-related meetings over the course of the study in order to decrease participant reactivity.

\section{Procedure}

After completion of an IRB approved consent form, smartphones were distributed to participants. The phones had unlimited text messaging and data services, along with 450 rollover minutes of voice service. Participants were not told how to use their device and no information on the specific purpose of the study was given, except that we were recording their usage data in an anonymized manner to understand smartphone usage. Participants were required to use the instrumented iPhones as their primary mobile phone during the entire one-year study period. At the end of the year, we administered the addiction survey. Students who completed the study were allowed to keep the iPhone as added compensation for their participation.

\section{RESUlTS}

A total of 21 of the 34 participants $(62 \%)$ agreed or strongly agreed they were addicted to their iPhones. We grouped these users together based on their agreement to at least some level of addiction to their smartphones and labeled this group "SA" for Self-reported Addiction. Of these 21 participants, 12 were male and nine were female.

The other 13 participants (i.e., NAs for Non-Addicts) did not agree at any level that they were addicted to their iPhones (i.e., they strongly disagreed, disagreed, or neither agreed or disagreed). Seven of these users were male and the other six were female. We did not find any notable differences in the demographics within either of these groups.

One participant within the SA group considered his addiction problematic and, as we describe in more detail below, his usage data was considered outlying. We removed his data from the comparative analyses between SAs and NAs, but focus on his usage in a separate section. Every other user in the SA reported his or her addiction was not problematic.

SAs differed from NAs in responses to several items on the SAMI, primarily in their perceived ability to control the craving to check their devices and their desire to spend as much time as possible on the device (Table 1). SAs also perceived more anxiety when they could not turn on their devices or check their favorite app. Many items did not yield differences. For instance, participants generally agreed their iPhones were difficult to turn off once on and useful for withdrawal/escape.

\section{A. Differences in recorded usage}

The self-reported addicts (SAs) and non-addicts (NAs) both used their phones frequently over the year-long study period. As can be seen in Table 2, SAs spent twice as much time on their phone compared to NAs. The former also launched applications much more frequently (nearly twice as often) compared to their NA peers. This difference is not driven by the number of applications installed by users as there were not significant differences between SAs and NAs in the number of applications installed. 
TABLE I.

ADDICTION ITEMS AND RESPONSES BY SELF-IDENTIFIED ADDICTED (SA) AND NON-ADDICTED (NA) INDIVIDUALS. RESPONSES ARE ON A 5 POINT SCALE, WHERE 5 IS 'STRONGLY AGREE'

\begin{tabular}{|c|c|c|c|c|c|}
\hline & \multicolumn{2}{|c|}{ SA } & \multicolumn{2}{|c|}{ NA } & \multirow[b]{2}{*}{$p^{*}$} \\
\hline & M & SD & M & SD & \\
\hline \multicolumn{6}{|l|}{ Inability to Control Craving } \\
\hline $\begin{array}{l}\text { You have been told that you } \\
\text { spend too much time on } \\
\text { your smartphone }\end{array}$ & 4.14 & 1.01 & 3.92 & 1.89 & .90 \\
\hline $\begin{array}{l}\text { You find yourself engaged } \\
\text { on the smartphone for } \\
\text { longer period of time than } \\
\text { intended }\end{array}$ & 3.31 & 1.27 & 3.49 & 1.02 & .93 \\
\hline $\begin{array}{l}\text { You can never spend } \\
\text { enough time on your } \\
\text { smartphone }\end{array}$ & 3.25 & 1.43 & 2.10 & 1.35 & $<.001$ \\
\hline $\begin{array}{l}\text { You have attempted to } \\
\text { spend less time on your } \\
\text { smartphone but are unable } \\
\text { to }\end{array}$ & 3.17 & 1.50 & 2.35 & 1.67 & .003 \\
\hline $\begin{array}{l}\text { You can control when you } \\
\text { check applications }\end{array}$ & 2.71 & 0.36 & 3.92 & 1.81 & $<.001$ \\
\hline $\begin{array}{l}\text { Checking your smartphone } \\
\text { satisfies a recurring urge }\end{array}$ & 3.02 & 0.73 & 1.99 & 1.03 & $<.001$ \\
\hline \multicolumn{6}{|l|}{ Feeling Anxious \& Lost } \\
\hline $\begin{array}{l}\text { You experience discomfort } \\
\text { when your phone is running } \\
\text { out of battery life. }\end{array}$ & 3.30 & 0.59 & 3.23 & 0.37 & .88 \\
\hline $\begin{array}{l}\text { You feel anxious if you have } \\
\text { not checked a favorite app } \\
\text { or switched on your } \\
\text { smartphone for some time. }\end{array}$ & 3.92 & 0.89 & 1.88 & 0.57 & $<.001$ \\
\hline $\begin{array}{l}\text { You find it difficult to switch } \\
\text { off your smartphone }\end{array}$ & 3.7 & 1.03 & 3.29 & 0.80 & .08 \\
\hline $\begin{array}{l}\text { You feel lost without your } \\
\text { smartphone }\end{array}$ & 2.19 & 0.96 & 2.01 & 1.19 & .71 \\
\hline \multicolumn{6}{|l|}{ Withdrawal/Escape } \\
\hline $\begin{array}{l}\text { You have used your } \\
\text { smartphone to } \\
\text { communicate to others } \\
\text { when you were feeling } \\
\text { lonely }\end{array}$ & 3.97 & 1.34 & 3.72 & 1.07 & .57 \\
\hline $\begin{array}{l}\text { Your smartphone is a } \\
\text { consistent companion }\end{array}$ & 3.61 & 1.11 & 3.24 & 1.20 & .46 \\
\hline $\begin{array}{l}\text { You have used your } \\
\text { smartphone to make } \\
\text { yourself feel better when } \\
\text { you were feeling down }\end{array}$ & 1.32 & 0.79 & '1.21 & 0.76 & .94 \\
\hline $\begin{array}{l}\text { You often fill your dead } \\
\text { time with smartphone use }\end{array}$ & 3.92 & 1.06 & 3.42 & 0.78 & .07 \\
\hline
\end{tabular}

In order to understand these differences between SAs and NAs, some applications were grouped based on category as defined by Apple for parsimony. For example, all gaming applications were combined. Independent $t-$ tests with Scheffe adjustments for multiple comparisons revealed a small subset of highly-used applications was used more by SAs according to our logged data (Table 2). SAs launched Mail, Facebook, Messages, and Safari much more frequently than NAs and spent more time on Mail, Facebook, Entertainment and Safari as compared to NAs.
Applications within categories such as Games and Education did not discriminate user groups, though SA and NA differences in the duration of game use approached the .05 alpha significance level $(p=.06)$.

In order to better understand how four of these specific applications were accessed longitudinally, Time per Interaction (TPI) rates were calculated for Mail, Facebook, Safari, and Messages applications and analyzed for each user. TPIs represent the number of seconds users spent on particular applications for each launch (TPI = Duration in Seconds / \# Launches). Lower TPIs reflect application usage that is shorter in duration and more frequently launched. Conversely, longer duration usage with less frequent application launches would yield higher TPI. NAs show higher TPI for Mail $(p=.015)$, Facebook $(p<.001)$ and Messaging $(\mathrm{P}<.001)$, while no difference between NAs and SAs exist for Safari TPI $(p=.63)$. TPIs across the duration of the study are shown in Figure 1.

TABLE II.

USAGE DATA MEAN DIFFERENCES AND STANDARD DEVIATIONS FOR SELF-REPORTED ADDICTED AND NON-ADDICTED STUDENTS. (*SCHEFFE ADJUSTED FOR MULTIPLE COMPARISONS)

\begin{tabular}{|c|c|c|c|c|c|}
\hline & \multicolumn{2}{|c|}{ Addicts } & \multicolumn{2}{|c|}{ Non-Addicts } & \multirow[b]{2}{*}{$p^{*}$} \\
\hline & Mean & SD & Mean & SD & \\
\hline Hours/Week & 8.02 & 4.13 & 4.32 & 4.80 & $<0.001$ \\
\hline $\begin{array}{c}\text { App } \\
\text { Launches/Week }\end{array}$ & 1059.55 & 287.71 & 592.81 & 249.76 & 0.001 \\
\hline Apps Installed & 139.67 & 50.77 & 103.50 & 41.32 & 0.22 \\
\hline $\begin{array}{c}\text { Apps } \\
\text { Uninstalled }\end{array}$ & 44.08 & 50.38 & 32.94 & 27.96 & 0.2 \\
\hline $\begin{array}{l}\text { Education } \\
(\mathrm{min} / \mathrm{wk})\end{array}$ & 2.79 & 1.33 & 2.09 & 3.25 & 0.39 \\
\hline $\begin{array}{c}\text { Education } \\
\text { (launches/wk) }\end{array}$ & 2.19 & 2.46 & 1.86 & 1.07 & 0.65 \\
\hline $\begin{array}{c}\text { Email } \\
(\mathrm{min} / \mathrm{wk})\end{array}$ & 46.16 & 23.56 & 27.99 & 15.48 & 0.03 \\
\hline $\begin{array}{c}\text { Email } \\
\text { (launches/wk) }\end{array}$ & 60.86 & 43.44 & 31.97 & 19.31 & 0.04 \\
\hline $\begin{array}{l}\text { Entertainment } \\
(\mathrm{min} / \mathrm{wk})\end{array}$ & 5.94 & 10.20 & 16.45 & 15.62 & 0.04 \\
\hline $\begin{array}{l}\text { Entertainment } \\
\text { (launches/wk) }\end{array}$ & 6.66 & 10.07 & 1.61 & 1.15 & 0.09 \\
\hline $\begin{array}{l}\text { Facebook } \\
\text { (min/wk) }\end{array}$ & 77.87 & 51.24 & 24.76 & 23.13 & .008 \\
\hline $\begin{array}{c}\text { Facebook } \\
\text { (launches/wk) }\end{array}$ & 45.81 & 29.77 & 20.96 & 22.47 & 0.03 \\
\hline $\begin{array}{c}\text { Games } \\
\text { (minutes/wk) }\end{array}$ & 104.30 & 106.70 & 81.18 & 94.34 & 0.06 \\
\hline $\begin{array}{c}\text { Games } \\
\text { (launches/wk) }\end{array}$ & 14.89 & 12.23 & 19.39 & 33.15 & 0.67 \\
\hline $\begin{array}{l}\text { Text Messages } \\
\text { (minutes/wk) }\end{array}$ & 161.30 & 93.21 & 119.13 & 80.22 & 0.19 \\
\hline $\begin{array}{l}\text { Text Messages } \\
\text { (launches/wk) }\end{array}$ & 189.17 & 99.88 & 87.18 & 46.77 & 0.004 \\
\hline $\begin{array}{c}\text { Web } \\
\text { (minutes/wk) }\end{array}$ & 70.66 & 36.61 & 33.86 & 34.39 & 0.01 \\
\hline $\begin{array}{c}\text { Web } \\
\text { (launches/wk) }\end{array}$ & 34.95 & 17.51 & 15.77 & 12.32 & 0.005 \\
\hline
\end{tabular}




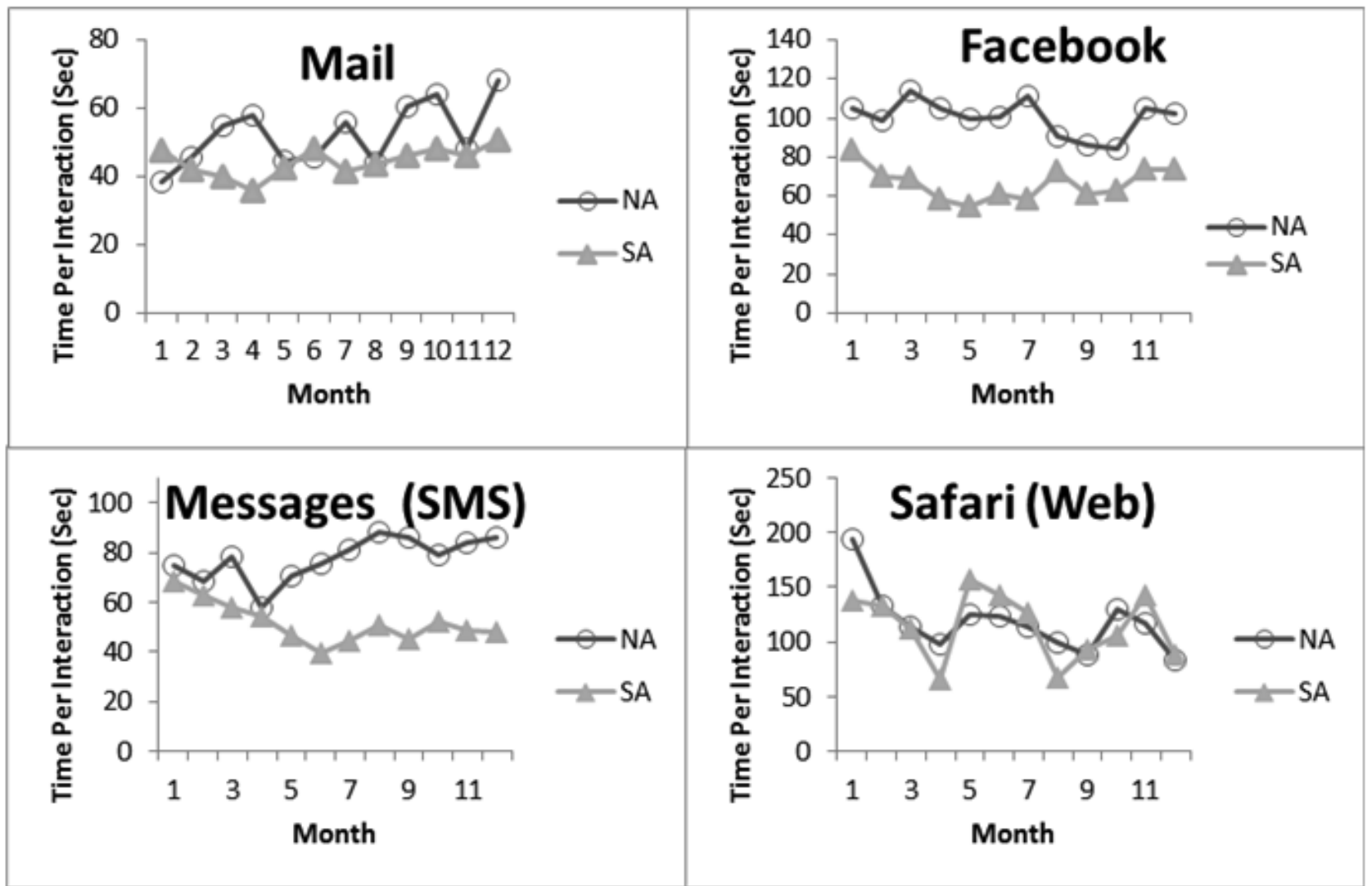

Figure 1. Time per interaction (in seconds) by month for Mail, Facebook, Messages, and Safari Applications.

\section{B. Problematic addiction}

Although there was high variability across users, the one individual who reported a problematic addiction to smartphone use was well beyond three standard deviations from the upper hinge in volume of usage. This participant reported that checking the smartphone was an uncontrollable urge and yielded an average of 122 application launches per day, equivalent to launching an application every eight minutes over the course of a normal 16 hour day. The Web was the most frequently launched application, and use was concentrated on just a few specific sites (one was adult oriented). These few sites were visited over 3,000 times throughout the course of the study (8.2 visits/day) starting almost immediately after we handed out the phones. Perhaps most surprising was this participant's rate of sending and receiving text messages. During the five busiest months, this participant averaged 220 text messages sent and received per day (one every four minutes).

\section{DISCUSSION}

We found that more than half of our users self-reported an addiction to their iPhone to at least some degree. These users launched applications on their devices much more than the other users that reported they were not addicted. Additionally, their average usage was two times more than their NA peers. At the broadest level, this study suggests that users who accessed their device more and for longer periods of time are aware of their addictive behavior and, in general, did not think it was problematic. Additionally, lower TPI rates exhibited by SA users for mail, Facebook and Messaging suggest that smartphones seem to afford short and fragmented interactions perhaps leading to habitual patterns of usage that may become difficult to control over time.

Participant reports suggest this is due to habitual checking behaviors, a finding supported by other research [25]. However, an alternate explanation is that NAs could have used these applications for more productive reasons related to the function of the application than did SAs. For example, using the Mail application to view a new message or compose an email is a more utilitarian use of the application that requires more time relative to habitual checking of any new emails that have arrived. It might also be that SA participants could have saved longer tasks such as composing or reading a long message for larger format computers (e.g., a laptop).

We are unable to say for certain what is driving the differences in TPI rates in these most popular applications. However, it appears that lower TPIs are one important indication of smartphone addiction. Time-inconsistent preferences and automaticity are two theories that provide underlying support for this type of habitual and unconsciously automatic behavior $[26,27]$. Web TPI did not show this trend, and this might be because the longer average session times for the web attenuate the effect.

Specific application usage discriminated users that perceived themselves as more addicted to their smartphones compared to others. To our surprise, gameplaying did not discriminate addicted users from nonaddicted users. Instead, the web, Facebook, SMS, and Mail were the applications that were used more by SAs compared to NAs. It could be argued that the SA users in this study were not addicted to these apps at all, but rather were instead exhibiting a (normal) desire to stay connected to their friends, and that NAs were actually low 
on social needs of this type. This persistent checking of the phone might be viewed by these SAs as being analogous to maintaining a conversation in a room full of friends. This might also suggest that SAs were simply more connected socially than NAs. However, this hypothesis was not reflected in the number of friends they contacted via their phones. Survey and logged data showed no differences between SAs and NAs in their number of Facebook friends $(p=.83)$ or Mail contacts $(p$ $=.79$ ). Of course, they could have been more connected in the type or depth of these relationships; we did not collect these kinds of data.

Telemetric data did reveal that SAs opened either Facebook or Mail applications before other applications when using their iPhones. Specifically, SAs accessed at least one of these two applications immediately after turning on their iPhones $72 \%$ of the time. NA interactions with their iPhones that started with one of these two applications only occurred $48 \%$ of total usage. This behavior pattern suggests that SA users were habitually checking these two applications, as compared to NAs who launched a wider range of applications immediately after accessing their device.

The problematic SA user reported that phone checking satisfied an uncontrollable urge, but some level of this urge was evident across all SA participants. In a sense, the smartphone itself did not seem like the source of the addiction, but rather the content to which the phone provides access. Similar to previous studies on internet addiction [24], the smartphone seemed to be a vehicle to addictive content and not the cause of the addiction itself.

We believe that this is a difference without a distinction - smartphones allow for continuous access to the Internet, and so users can utilize the technology satisfy their urges to access content in most personal and professional environments. In this sense, the fact that the smartphone is ubiquitously available could feed the addiction to an individual's content of choice. Previous addictions that could only be fed at a desktop can now be satisfied whenever and wherever one gets the urge.

Although the benefits to these devices to support humans are well established (e.g., in education [28] and medicine [29]), our results show that this continuous access could afford more addictive behaviors in a wider variety of settings. Indeed, users no longer need a sustained period of time, access to electrical outlets, or a full computer to get their email or Facebook "fix" but can simply reach into their pockets and pull out an engaging device to achieve the same end. With this in mind, smartphones as a persistent enabler should be of note to clinicians. To some degree, we believe that the device, and the related content providers, share some of the responsibility for these emerging addictive behaviors. Content is constantly updated, email is received at a steady pace and social media posts appear with high regularity, and this information push promotes these behaviors. Consider the time before this always-available platform; the newspaper arrived once a day (or twice in large cities), mail was delivered once a day and social conversations were confined to those occasions when you happened to be in the physical presence of your close acquaintances. Smartphones, and their access to constantly changing information has altered people's access to information, and this may be why these addicting behaviors have begun to emerge.
On the other side of the coin, both NA and SA participants reported their devices were helpful to fill dead-time, keep in touch with their social network when lonely, and act as their continuous companion. These positive aspects of smartphones should not be ignored. Smartphones provide access to helpful resources in a number of contexts, in addition to addictive content, that can be helpful for a wide range of problematic thoughts and behaviors. Our research agrees with [30], suggesting that smartphones can be harnessed to promote positive behaviors and, perhaps, in the near future, be used as a sensor to help to this end. We purport that qualitative research like [30], as well as combined quantitative and qualitative studies described here, will be helpful to make this future a reality.

\section{A. Limitations}

This was an exploratory study using a blended approach and there are several limitations to the results presented above. First and foremost is the small sample size. Clearly, the 34 users assessed here are quite small in number and not completely representative of the larger population of smartphone owners in terms of their demographics and context of use. Indeed, college students are a particularly vulnerable group to this type of addiction [31, 32]. However, the telemetric usage data presented here provides more depth and precision than typical survey-based research and helps to mitigate the small sample size [19]. The sample size also provided enough power to detect differences between groups.

Second, we relied on self-reports for parts of our data collection. There are well-known concerns about these kind of data [18], but believe those problems are mostly mitigated in this research because we did not ask for estimates of quantifiable behaviors (e.g. "How often do you check your message per day?") as those data were collected by the device itself. Rather, we asked more qualitative questions that require human interpretation to answer (e.g. "how difficult do you find it to switch off your smartphone?"). Finally, as pointed out in the introduction, there are particular challenges with the term "addiction". We use the term in this paper, because it is the term used in much of the literature describing excess use of technology. Indeed, even the measurement scales used to assess this overuse have the word addiction in their titles [21, 22]. We make no claims to the clinical diagnosis of smartphone addiction, as it is not currently included in the DSM-5, but instead rely on its colloquial use as a common description of behaviors that are at once reinforcing and potentially problematic.

\section{CONCLUSIONS}

In conclusion, we explored the topic of smartphone addiction using an emerging naturalistic and longitudinal telemetric approach. These data should be interpreted with caution due to the small sample size and potentially more vulnerable demographic. Still, this study provides a first glimpse into the addictive nature of smartphones as indicated by real usage data combined with survey data. This kind of behavioral logging data provides more precision regarding what addicted users actually do on their devices.

Future studies, with larger sample sizes, should employ a psychometric approach to understand the latent constructs that underlie these behaviors, the behavioral 
profiles of SAs, and the psychological consequences of having a pathological-level of smartphone addiction. Correlating psychometric data with specific aspects of smartphone usage seems to be an interesting way ahead.

Finally, this research raises particular questions about future directions for clinical psychology. Should technology and analytics be used to help predict and treat behavioral disorders? It could be that these kinds of analytics collected from a smartphone could be used to diagnose or predict the onset of certain disorders and provide interventions and treatments.

\section{REFERENCES}

[1] Strategy Analytics (2012). Worldwide Smartphone Population Tops 1 Billion in Q3 2012. Wireless Smartphone Strategies. http://blogs.strategyanalytics.com/WDS/post/2012/10/17/Worldwi de-Smartphone-Population-Tops-1-Billion-in-Q3-2012.aspx.

[2] Do TMT, Blom J, Gatica-Perez D. Smartphone usage in the wild: a large-scale analysis of applications and context. Proceedings of the 13th international conference on multimodal interfaces 2011:353-360. http://dx.doi.org/10.1145/2070481.2070550

[3] Farago P. (2012). iOS and Android Adoption Explodes Internationally. http://blog.flurry.com/bid/88867/iOS-andAndroid-Adoption-Explodes-Internationally

[4] Newark-French C. (2011) Mobile apps put the web in their rear view mirror. http://blog.flurry.com/?month=6\&year=2011.

[5] Ofcom (2012) Communications Market Report. United Kingdom Office of Communications. http://stakeholders.ofcom.org.uk/market-data-research/marketdata/communications-market-reports/cmr12/.

[6] Telenav (2011). Survey Finds One-Third of Americans More Willing to Give Up Sex Than Their Mobile Phones. http://www.telenav.com/about/pr-summer-travel/report20110803.html.

[7] Perez EJP, Monje MTR, De Leon JMRS. Mobile phone abuse or addiction. A review of the literature. Adicciones 2012; 24(2);139152.

[8] Griffiths MD. Internet and video-game addiction. In Essau CA, ed. Adolescent addiction: Epidemiology, assessment and treatment. London: Academic Press. 2008; 231-267. http://dx.doi.org/10.1016/B978-012373625-3.50010-3

[9] Griffiths M. Does Internet and Computer "Addiction" Exist? Some Case Study Evidence. CyberPsychology \& Behavior 2000; 3(2): 211-218. http://dx.doi.org/10.1089/109493100316067

[10] Roberts JA, Pirog SF. A preliminary investigation of materialism and impulsiveness as predictors of technological addictions among young adults. Journal of Behavioral Addictions 2013; 2(1):56-62. http://dx.doi.org/10.1556/JBA.1.2012.011

[11] Yellowlees PM, Marks S. Problematic Internet use or Internet addiction? Computers in Human Behavior 2007; 23(3):1447-1453. http://dx.doi.org/10.1016/j.chb.2005.05.004

[12] Backer-Grøndahl A, Sagberg F. Driving and telephoning: Relative accident risk when using hand-held and hands-free mobile phones. Safety Science 2011; 49(2): 324-330. http://dx.doi.org/10.1016/j.ssci.2010.09.009

[13] Beranuy M, Oberst U, Carbonell X, Chamarro A. Problematic Internet and mobile phone use and clinical symptoms in college students: The role of emotional intelligence. Computers in Human Behavior 2009; 25:1182-1187. http://dx.doi.org/10.1016/j.chb.2009.03.001

[14] Billieux J, Van der Linden M, Rochat, L. The role of impulsivity in actual and problematic use of the mobile phone. Applied Cognitive Psychology 2008; 22: 1195-1210. http://dx.doi.org/10.1002/acp.1429

[15] Chóliz M. Mobile phone addiction: a point of issue. Addiction 2010;105:373-374. http://dx.doi.org/10.1111/j.13600443.2009.02854.x
[16] Park WK. (2005) Mobile Phone Addiction. In: Ling R, Pedersen P, eds. Mobile Communications: Re-negotiation of the Social Sphere. London: Springer-Verlag, pp. 253-272. http://dx.doi.org/10.1007/1-84628-248-9 17

[17] James D. (2012) Problematic use of mobile phones: Measuring the behaviour, its motivational mechanism, and negative consequences. Doctoral dissertation, Queensland University of Technology Brisbane, Australia. http://eprints.qut.edu.au/54749/ 1/Dianna James Thesis.pdf.

[18] Podsakoff PM. MacKenzie SB, Lee JY, Podsakoff NP. Common method biases in behavioral research: a critical review of the literature and recommended remedies. Journal of applied psychology 2203; 88(5): 879-903. http://dx.doi.org/10.1037/00219010.88.5.879

[19] Tossell CC, Kortum P, Shepard CW, Rahmati A, Zhong L. Getting Real: A Naturalistic Methodology for Using Smartphones to Collect Mediated Communications. Advances in Human Computer Interaction 2012: 1-10. http://dx.doi.org/10.1155/2012/815972

[20] Shepard C, Tossell C, Rahmati A, Zhong L, Kortum P. LiveLab: Measuring Wireless Networks and Smartphone Users in the Field. ACM SIGMETRICS Performance Evaluation Review 2010; 38(3): 15-20. http://dx.doi.org/10.1145/1925019.1925023

[21] Koo HY. Development of a cell phone addiction scale for Korean adolescents. Journal of Korean Academy of Nursing 2009: 39(6): 818-828. http://dx.doi.org/10.4040/jkan.2009.39.6.818

[22] Young KS. Internet addiction: The emergence of a new clinical disorder. CyberPsychology and Behavior 1998; 1(3): 237-244. http://dx.doi.org/10.1089/cpb.1998.1.237

[23] Khazaal Y, Billeux J, Thorens G, Khan R, Louati Y, Scarlatti E, et al. French validation of the Internet Addiction Test. CyberPsychol Behav 2008; 11:703-6. http://dx.doi.org/10.1089/cpb.2007.0249

[24] Widyanto L, Griffiths M. Internet Addiction: A Critical Review. International Journal of Mental Health and Addiction 2006; 4(1): 31-51. http://dx.doi.org/10.1007/s11469-006-9009-9

[25] Lee YK, Chang CT, Lin Y, Cheng ZH. The dark side of smartphone usage: Psychological traits, compulsive behavior and technostress. Computers in Human Behavior 2014; 31: 373-383. http://dx.doi.org/10.1016/j.chb.2013.10.047

[26] Hoch SJ, Loewenstein GF. Time-Inconsistent Preferences and Consumer Self-Control. Journal of Consumer Research 1991: 17(4): 492-507. http://dx.doi.org/10.1086/208573

[27] Morsella E, Bargh JA. (2011). Unconscious action tendencies: Sources of 'un-integrated'action. In: Decety J, Cacioppo JT, eds. The Oxford handbook of social neuroscience, New York, NY: Oxford University Press, pp. 335-347. http://dx.doi.org/10.1093/oxfordhb/9780195342161.013.0022

[28] Guy R, Chack C, Ngesi N, Mehigan TJ, Pitt I, Simbulan IS, Schleser M, Williams PW. (2010) Mobile Learning Reviewed. In: Guy R, ed. Mobile learning: Pilot projects and initiatives. Santa Rosa, CA.: Informing Science Press, pp 59-74.

[29] Ozdalga E, Ozdalga A, Ahuja N. The smartphone in medicine: a review of current and potential use among physicians and students. Journal of Medical Internet research 2012: 14(5). http://dx.doi.org/10.2196/jmir.1994

[30] Dennison L, Morrison L, Conway G, Yardley L. Opportunities and challenges for smartphone applications in supporting health behavior change: Qualitative study. Journal of Medical Internet Research 2013; 15(4): e86. http://dx.doi.org/10.2196/jmir.2583

[31] Jenaro C, Flores N, Gómez-Vela M, González-Gil F, Caballo C. Problematic Internet and cell-phone use: Psychological, behavioral, and health correlates. Addiction Research \& Theory 2007; 15(3): 309-320. http://dx.doi.org/10.1080/16066350701350247

[32] Kandell JJ, Internet Addiction on Campus: The Vulnerability of College Students. CyberPsychology \& Behavior 1998; 1(1): 1117. G. Eason, B. Noble, and I. N. Sneddon, "On certain integrals of Lipschitz-Hankel type involving products of Bessel functions," Phil. Trans. Roy. Soc. London, vol. A247, pp. 529-551, April 1955. 


\section{AUTHORS}

Chad Tossell is with the US Air Force Research Laboratory, Wright-Patterson AFB, OH, USA. (e-mail: chad.tossell@us.af.mil)

Philip Kortum is with the Department of Psychology at Rice University, Houston, TX 77005 USA. (e-mail: pkortum@rice.edu).

Clayton Shepard is with the Department of Electrical and Computer Engineering at Rice University, Houston, TX, USA. (e-mail: cws@rice.edu).
Ahmad Rahmati is with the Apple Corporation, Cupertino, CA, USA. Rice University, Houston, TX, USA. (e-mail: ahmad@rahmati.com).

Lin Zhong is with the Department of Electrical and Computer Engineering at Rice University, Houston, TX, USA. (e-mail: lzhong@rice.edu).

This work was supported in part by NSF IIS/HCC 0803556. Submitted, December 4, 2014. Published as resubmitted by the authors 23 March 2015 